\title{
The Power of Asking: How Communication Affects Selfishness, Empathy, and Altruism*
}

\author{
James Andreoni ${ }^{1}$ Justin M. Rao ${ }^{2}$ \\ ${ }^{1}$ Department of Economics, University of California, San Diego and NBER \\ ${ }^{2}$ Yahoo! Research Labs, Santa Clara, CA
}

December 15, 2010

\begin{abstract}
To understand the "pure" incentives of altruism, economic laboratory research on humans almost always forbids communication between subjects. In reality, however, altruism usually requires interaction between givers and receivers, which clearly must influence choices. Charities, for example, speak of the "power of asking." Indeed, evolutionary theories of altruism are built on human sociality. We experimentally examine communication in which one subject allocates $\$ 10$ between herself and a receiver, and systematically altered who in the pair could speak. We found that any time the recipient spoke, giving increased - asking is powerful. But when only allocators could speak, choices were significantly more selfish than any other condition. When empathy was heightened by putting allocators "in the receivers shoes," giving appeared as if recipients had been able to ask, even when they were silent. We conclude that communication dramatically influences altruistic behavior, and appears to largely work by heightening empathy.
\end{abstract}

\footnotetext{
${ }^{*}$ We would like to send thanks to Ben Cowan and Megan Ritz for research assistance, to Susan Henning, William Harbaugh, Zack Grossman and two anonymous referees for useful comments, and to the National Science Foundation (SES 0962484) and the Science of Generosity Initiative for generous financial support.
} 


\section{Introduction}

Laboratory experiments on altruistic behavior have almost exclusively studied subjects in isolation from social interaction in order to protect anonymity and identify "pure" incentives to give. Yet in the real world giving occurs in the context of a social interaction between giver and receiver and the incentives to give are affected by the social factors surrounding this interaction. A common finding is that most subjects exhibit significant altruism and inequity aversion (Fehr and Schmidt, 1999; Bolton and Ockenfels, 2000; Andreoni and Miller, 2002). Recent work has linked these preferences to brain activity (in areas associated with rewards) arguing in favor of "hardwired egalitarianism" (Tricomi et al., 2010). However, in the United States and other industrialized countries there is vast inequality in consumption, while charitable giving is only 1$2 \%$ of income (Andreoni, 2006). How can we reconcile a taste for equality with behavior that indicates people generally tolerate a great deal of inequality in their daily lives? In this paper we argue that while humans do have a strong capacity to behave altruistically, selfishness typically predominates. Furthermore, social cues have evolved so that altruistic behavior is not expressed indiscriminately, but rather is likely to be expressed when it is instrumental in serving other selfish (or imperfectly altruistic) ends.

To test this hypothesis, we use a subtle manipulation of a single social factor: verbal communication. Communication is a natural social cue because it forms the backbone of the interaction between giver and receiver. Indeed a leading theory on the origins of verbal communication is that it arose out of gestural communication to facilitate mutually beneficial coordinative acts (Grice, 1957; Tomasello, 2008). Furthermore, verbal communication typically entails recursive belief formation about the subject matter and language conventions. In Experiment 1 of our study, we used the Dictator Game (DG) and systematically altered who in the pair (one, both and the order) could send a message. We find that in the condition in which only the allocator could speak, only $6 \%$ of the endowment was donated, which was significantly lower than the no-communication baseline of $15 \%$. This is the condition in which roles were most asymmetric in the social interaction. In stark contrast, anytime the recipient spoke, at least $24 \%$ of the endowment was passed asking is indeed powerful. Interestingly, giving was highest in the conditions that involved two-way communication. In these conditions $30 \%$ of the endowment was passed on average, even when the allocator was first to speak.

To help understand verbal expression and motivations, third-party reviewers performed textual analysis. We find that content of the messages from allocators significantly depended on the presence of an "ask." For instance, fairness was significantly more likely to be spoken about in the presence of an ask, whereas luck was significantly less likely. Interestingly, the content did not differ based on whether the allocator was responding directly to an ask, or sending a message knowing they would receive a reply before they made their final allocation decision. In the latter condition allocators did a good job of "anticipating the ask" (the modal ask focused on fairness and equal division) and tailored their message appropriately. Conversely, in the one-way communication condition in which only allocators spoke, messages were one-sixth as likely to mention fairness and typically offered an apology.

The results of Experiment 1 are stark. When only the allocator could speak, he typically was very selfish and issued a hollow apology, but the apologetic "blocking mechanism" was not employed in the 
presence of an ask; in this case allocators' messages displayed more of an understanding of the other's position. This finding, along with recent findings in the neuroeconomics literature linking areas of the brain associated with communication and social contexts with empathic concern (De Vignemont and Singer, 2006; Decety and Jackson, 2006; Moll et al., 2006; Hare et al., 2010) led us to hypothesize that communication from a recipient facilitates altruism through feelings of empathy. In Experiment 2 empathy was heightened by putting allocators "in the receivers shoes." Experiment 2 used modified version of the two conditions involving one-way communication in Experiment 1. Before roles were determined, all subjects filled out a decision form for each role. Then roles were randomly determined and unused decision forms were set aside. In the condition in which only the allocator could speak, the allocations and verbal content appeared as if recipients had been able to ask. Making choices from the position of both roles and being subjected to a verbal request led to nearly identical pass distributions. Our interpretation is that asking leads the allocator the actively consider and identify with the role of the recipient; we call this feeling "empathy."1 However, there are limits in terms of the associated effects on giving. In both experiments, requests for more than equal division ("selfish requests") lead to average pass levels significantly below the baseline. ${ }^{2}$

There is considerable evidence that feelings of empathy are strongly connected to altruistic and prosocial behavior (Batson et al., 1988; Batson, 2002; De Vignemont and Singer, 2006; Preston and de Waal, 2002). The "empathy-altruism hypothesis" posits that feelings of empathy are the primary explanation for altruistic acts for which the agent does not expect to receive compensating material benefits through reciprocity or the absence of sanctions. Laboratory experiments have found that altruistic behavior is promoted through the reduction of social distance (Roth, 1995; Hoffman et al., 1996; Bohnet and Frey, 1999) and making potential victims of selfishness more identifiable (Schelling, 1968; Small and Loewenstein, 2003). ${ }^{3}$ However, recent work has argued that selfish concerns such as guilt aversion (Charness and Dufwenberg, 2006; Battigalli and Dufwenberg, 2007) and self-image maintenance through self-signaling (Bodner and Prelec, 2003) and self-deception (Dana et al., 2007) can help explain seemingly altruistic behavior. Although the idea has not received explicit attention in the literature, it indeed may be the case that empathy operates through these channels. For example, it may raise the cost of self-deception. ${ }^{4}$ In Section 4 we discuss this possibility.

Given the economic and social importance of altruistic behavior, several theories have been proposed to explain the origins and evolution of altruism and cooperation in humans. Leading theories include kin selection (Hamilton, 1964), reciprocity (Nowak and Sigmund, 2005; Trivers, 1971) and norm adherence through sanctions (Boyd and Richerson, 1992; De Quervain et al., 2004; Gurerk et al., 2006). These theories provide a sound theoretical backbone for the existence of altruistic behavior in the human psychological composition and can help explain why people are often generous in situations in which the conditions of the theories are not met (e.g. acts of altruism towards non-kin, in the absence of reciprocity/sanctions or

\footnotetext{
${ }^{1}$ In a formal model, one could define empathy as inversely proportional to the variance of one's belief about another's expectations.

${ }^{2}$ Rankin (2006) also finds this result for numerical requests.

${ }^{3}$ Laboratory work has also demonstrated that altruistic behavior can be elicited through self-interest related channels. Examples include monetary rewards/punishment (Gurerk et al., 2006; Fehr and Fischbacher, 2003), emotion-based rewards/punishment (Masclet et al., 2003) and appealing to subjects' desire to maintain a positive social image (Andreoni and Bernheim, 2009).

${ }^{4}$ We thank a referee and editor for this helpful suggestion.
} 
one-time gifts to strangers). However, they rely in two important ways on the fact that humans are a social species. First, the social nature of human interaction allows for the underlying theoretical mechanisms to function (for instance communication allows for reputation building and reciprocity). Tomasello (2008) shows that the differences in altruism between great apes (which exhibit effectively no pure altruism) and humans can be linked to humans' advanced social capacities such as verbal communication. Secondly, the theories rely on humans to respond to social cues so that they are not indiscriminately altruistic and hence perish quickly.

Neuroimaging studies provide support for both points. The evidence indicates that the human brain is wired so that the decision processes underlying altruistic behavior and socialization are strongly linked (Harbaugh et al., 2007; Moll et al., 2006; Hare et al., 2001). In addition to the neural evidence, the reasoning underlying our argument that communication affects empathy and elicits altruism rests on a unique feature of human communication known as "recursive mindreading" or "role imitation reversal" (Hare et al., 2001; Akhtar et al., 1996). That is, in any dyad, person 1's communicative acts depend critically on 1's beliefs concerning person 2's beliefs and $2 \mathrm{~s}$ beliefs about $1 \mathrm{~s}$ beliefs, and so on. In economics, this is the familiar notion of iterative belief formation, which underlies game theoretic solution concepts. ${ }^{5}$ This recursively structured belief formation helps establish the "joint attentional frame" necessary for effective, high level communication (Clark, 1992).

In Experiment 1, communication from recipients, regardless of the order of who spoke, led to a "conversation" more likely to be centered around fairness and more generous behavior. This is surprising in that the content of requests is quite predictable; one would presumably expect a message center around fairness and a numerical request for equal division and this is exactly the modal message. Despite the predictability of the request, allocators in the condition in which only they got to speak behaved more selfishly than the baseline and sent messages centered around luck or apology — "asking for the obvious" matters. Experiment 2 indicates that it matters through the elicitation of empathy associated with the belief formation necessary for communication. In the discussion section we explore the possibility that empathy affects behavior through self-interested channels such as guilt aversion and self-deception.

The remainder of the paper proceeds as follows: Section 2 presents the experimental design, Section 3 provides the results, Section 4 contains a discussion and Section 5 concludes.

\section{Experimental Design}

In order to test our hypothesis that verbal communication has evolved to mediate the expression of altruism, we manipulated the communication available to subjects playing a modified version of the dictator game (DG). The DG is regarded as the standard decision task to study altruism in experimental economics (Forsythe et al., 1994; Andreoni and Miller, 2002). In the baseline version of the game, two subjects share 100 money units (MUs). MUs are always worth $\$ 0.10$ to all subjects. One subject is randomly assigned the role of allocator and the other is assigned the role of receiver. The allocator initially holds all 100 MUs and

\footnotetext{
${ }^{5}$ In fact, behavioral models of bounded rationality, such as level-k thinking, arrive at new equilibria by limiting the number of iterative steps, see for instance Crawford and Iriberri (2007).
} 
Stage 1: Person $R$ moves.

\begin{tabular}{|l|}
\hline R's Request to A: Please fill out your decision in Stage 2 this way: \\
Of the 100 tokens, I choose to hold__ for myself and pass ___ Person R. \\
\hline In the space below, you may record a message to Person A. \\
\hline \\
\hline
\end{tabular}

Figure 1: Decision form in which the recipient first sent request (Ask or Ask then Explain)

makes the decision of how many MUs pass to the receiver, without communication between subjects. The allocator's decision is final and completely determines monetary payoffs.

We conducted two experiments building on the baseline DG without communication. Experiment 1 included 238 subjects who played two rounds of the DG with different anonymous partners. Roles remained constant across rounds. In addition to the baseline DG were four conditions that allowed subjects, to varying degrees, to communicate via written verbal and numerical messages. Communication was always optional and free form.

In condition "Ask", $(A)$, the receiver wrote a verbal message along with a numerical "pass request," which the allocator read before making the pass decision. After the allocator made the pass decision the receiver was informed of the payoffs for the game. In "Explain" $(E)$, the allocator sent a written verbal message along with the pass decision, however the receiver stayed silent. In "Ask then Explain" ( $A E)$, the receiver first sent a verbal message and numerical request and then the allocator recorded the pass choice accompanied by a verbal reply message. In "Explain then Ask" $(E A)$ the allocator first sent a verbal message along with a "non-binding allocation," the receiver then responded with a verbal and numerical request, after which the allocator determined final payoffs. The breakdown of subjects across condition was: Baseline 40, A 40, E 40, AE 80 and $E A 38$.

The subjects were not given any suggestions regarding the content of the messages; the only restriction prohibited the inclusion of identifying information or promises external to the laboratory. Anonymity was maintained in order to identify the effect of communication without confounding factors, such as reputation outside of the experiment, which are known to influence behavior in the DG (Roth, 1995). All instructions are available in the appendix. Figure 1 provides an example decision form.

Our secondary hypothesis is that communication from the recipient leads the allocator to consider the recipient's position more fully and this empathic consideration induces altruistic behavior. To directly test 
this hypothesis, Experiment 2 used augmented versions of $A$ and $E$ in which feelings of empathy were intentionally heightened. Before roles were determined, all subjects filled out decision forms for the first stage of both the $A$ and $E$ versions of the DG. One form $(E)$ placed the subject in the role of allocator and the other $(A)$ the role of receiver. For each version, the subjects were assigned different counterparts and we made this clear to the subjects in the instructions. The intent was to lead the subjects to "put themselves in the other's shoes," while maintaining one-way communication. After the Stage 1 decisions were made, role were randomly determined and we set aside the $A$ forms from allocators and $E$ forms from receivers. The remaining forms were then used to determine monetary payoffs. 40 subjects played a single round in this manner. It is important to note that despite filling out decisions for each role, each subject played only one role, which always involved one-way communication.

\section{Results}

\section{Experiment 1 Results}

Figure 2 presents mean amounts passed in Experiment 1 (panel A) and the fraction of all pass amounts equal to zero and to equal division on the right (panel B). The evidence is clear. Both the existence and structure of communication significantly influenced allocators' expressed altruism. In the no-communication baseline, allocators passed an average of 15.3 MUs. In $E$, allocators gave significantly less than the baseline (Wilcoxon rank-sum $z=-2.73, p<0.006$ ), chose fewer equal divisions $(t=-2.33, p<0.025$, two-tailed t-test, standard errors clustered by subject) and more zeros $(p<0.007)$. Conversely, in the twoway communication conditions ( $A E, E A$ ) allocators' transfer greatly exceeded the baseline (AE: $z=3.29$, $p<0.001$, EA: $z=2.04, p<0.041)$. Giving in $A$ was higher than the baseline and the difference becomes significant when we only consider requests for an even division or less $(z=1.965, p<0.049)$. A full comparison of conditions is given in Appendix Table 2.

In the conditions in which allocators "spoke" first, giving was very much a function of whether the communication was one-way $(E)$ or two-way $(A E, E A)$. Passes were on average over four and half times higher in $E A$ than in $E(E A$ mean $=27.0, E$ mean $=6.5 ; z=4.28, p<0.0001)$, while equal division was ten times more likely $(t=3.69, p<0.0004)$. In fact, the mean of the non-binding allocation from the first round of communication in $E A$ was 25.8 , far exceeding the mean pass in $E(z=4.41, p<0.0001){ }^{6}$

Table 1 examines whether the content of subjects' written communication was associated with pass behavior. Each message was evaluated for content by seven undergraduate reviewers (gender balanced to match the subject pool) who had no prior knowledge of the study. The communication items are intended to capture the basic content of a message. A message can fall into more than one category, or none at all. In a majority of cases, reviewer opinion was unanimous. In the remaining cases, the average rating was used. The instructions to reviewers are contained in the appendix.

The statistical tests in Table 1 compare communication in the two-way conditions to their one-way counterpart. Overall, allocator communication varied in ways consistent with the expressed altruism. Allocators

\footnotetext{
${ }^{6}$ Although the means of the non-binding and final allocation in $E A$ are not significantly different from each other, there is a significant majority of subjects shaded slightly up.
} 

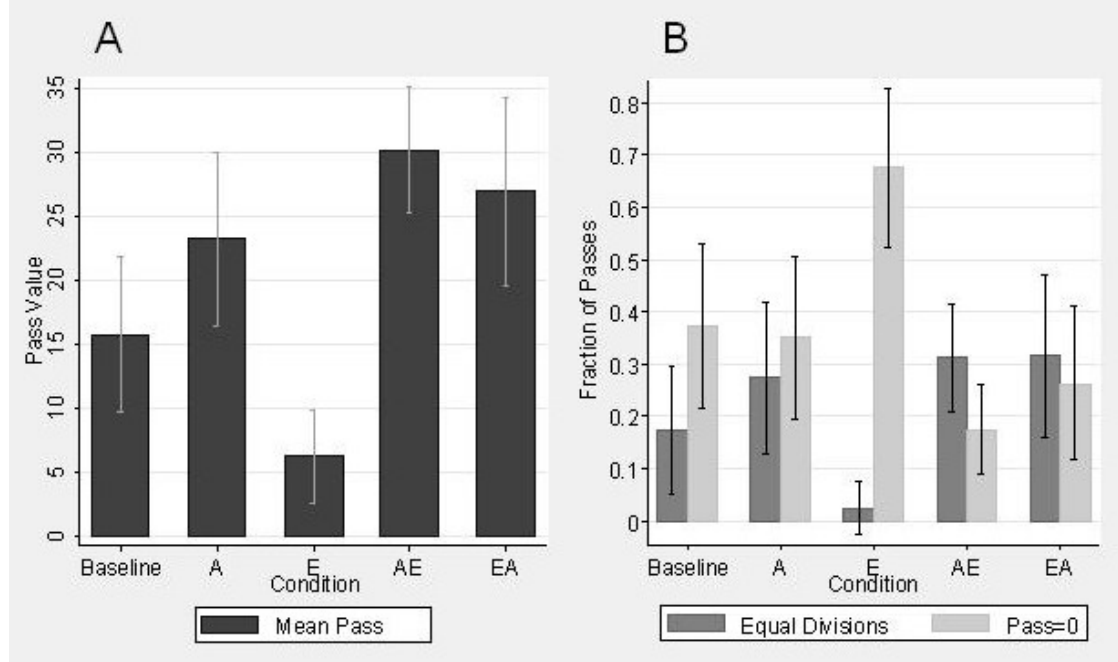

Figure 2: (A) Means of pass value by Experiment 1 condition: Baseline (no communication), $A$ (ask by recipients), $E$ (explain by givers), $A E$ (ask then explain), $E A$ (explain then ask). (B) Fraction of equal divisions and pass $=0$ by condition of Experiment 1 . The allocator determined the final allocation of 100 MUs between themselves and an anonymous partner (the receiver) by "passing" any value between 0 and 100 MUs. Bars give $+/-2$ s.e.

in $E A$ and $A E$ were more likely to express fairness and less likely to express remorse than allocators in $E$. These differences are large in magnitude and highly significant. Receivers' written messages (requests) varied by condition as well, while the numerical request did not. Receivers were significantly less likely to communicate flattery and acknowledge the allocator's power in the two-way conditions. These differences are most likely due to the more balanced nature of two-way communication. Unsurprisingly, the modal request in all conditions expressed fairness and called for an equal division. Also, the likelihood of using verbal communication at all was significantly higher in the two-way conditions.

Across conditions, allocators who expressed fairness behaved far more altruistically ( $n=48$, mean pass $=40.21)$ than those who did not $(n=110$, mean $=16.04, t=7.20, p<0.000)$. Conversely, remorse was associated with far lower pass values $(n=45$, mean $=10.42$, vs. $n=45$, mean $=28.54, t=4.93$, $p<0.000$ ). Conditional on the numerical request, the content of the request, as measured through the communication categories presented in Table 1, did not significantly affect allocator behavior. The quantile regression used to support this conclusion is contained in the appendix. The estimated coefficient on fairness was well within a standard error of zero (coeff. $-3.83, t=0.32, p<0.75$ ); there was sufficient variation to estimate this coefficient as $61.6 \%$ of subjects requesting an equal division mentioned fairness. ${ }^{7}$ None of the other categories approached standard significance levels as all were well within one standard error of zero. Perhaps paradoxically, the words themselves in requests do not appear to directly affect allocator behavior, but the existence of a request matters tremendously. ${ }^{8}$

\footnotetext{
${ }^{7}$ Including a term for fairness interacted with the level of the request yields a coefficient estimation of 0.81 , not significantly different from 0 .

${ }^{8}$ Rankin (2006) finds that numerical requests increase passes in an anonymous DG, but actually reduce passes when the inter-
} 
Table 1: Communication Content by Condition of Experiment 1

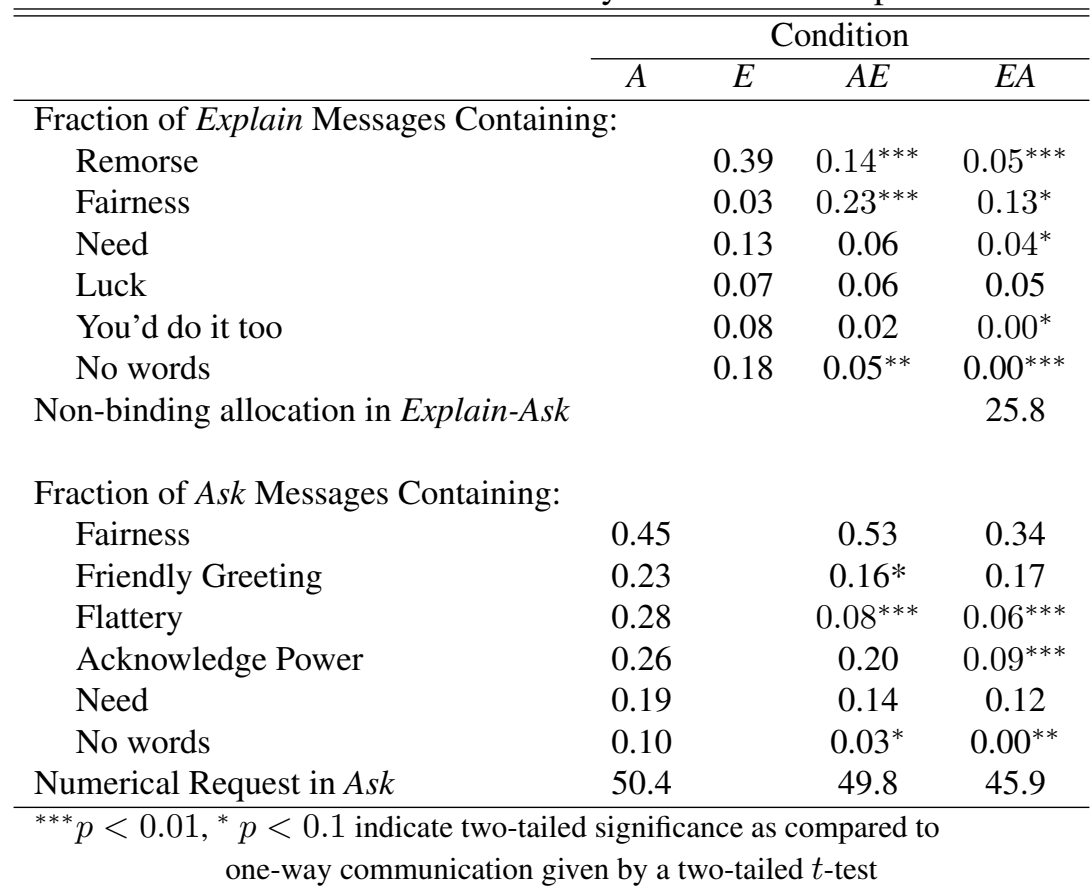

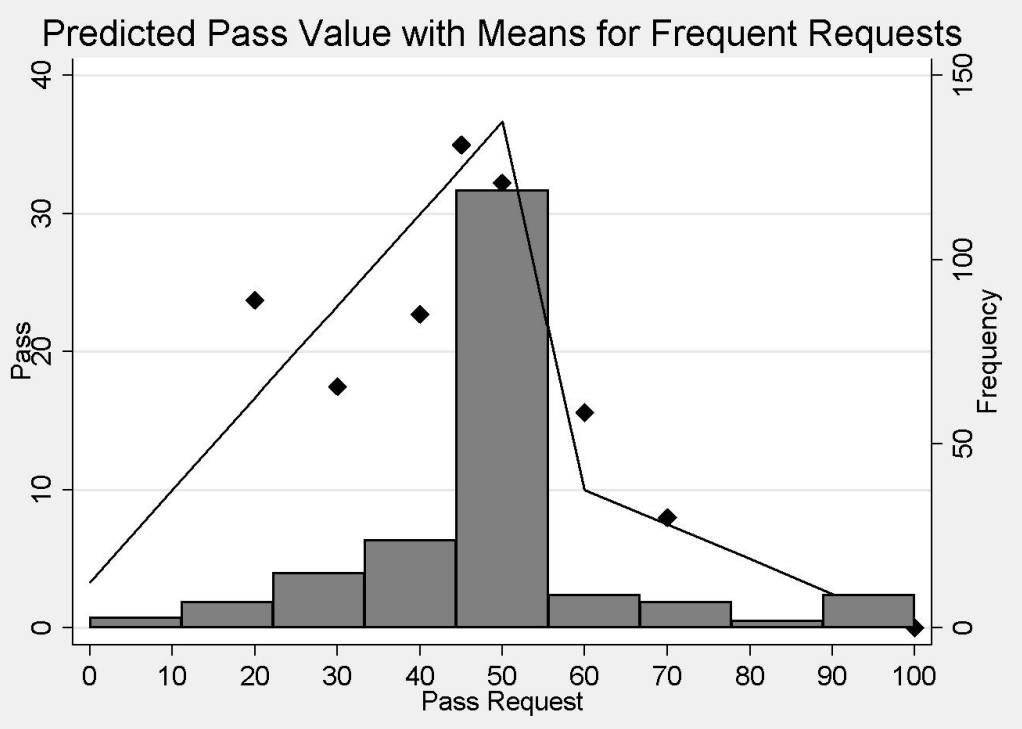

Figure 3: Bars: Frequency of pass requests (right axis), Line: L.A.D. fitted pass values as a function of numerical request (left axis), Diamonds: Mean pass values for relatively frequent requests (left axis) 
Table 2: Do You Get What You Ask For?

\begin{tabular}{|c|c|c|c|c|}
\hline \multirow{4}{*}{$\begin{array}{l}\text { Probability of pass }<r \\
\text { Mean pass }\end{array}$} & \multicolumn{4}{|c|}{ Request Category } \\
\hline & $r<40$ & $40 \leq r \leq 45$ & $r=50$ & $r>50$ \\
\hline & 0.50 & 0.74 & 0.58 & $0.95^{* * *}$ \\
\hline & 5.0 & 16.5 & 18.4 & 11.4 \\
\hline Probability of pass $=r$ & $0.13^{* *}$ & $0.15^{* *}$ & 0.39 & $0.05^{* * *}$ \\
\hline Mean pass & 15.0 & 40.0 & 50.0 & 80.0 \\
\hline Probability of pass $>r$ & $0.38^{* * *}$ & 0.11 & 0.03 & 0.00 \\
\hline Mean pass & 47.5 & 50.0 & 85.0 & $\mathrm{n} / \mathrm{a}$ \\
\hline$\%$ of Requests & $10.2 \%$ & $17.3 \%$ & $59.0 \%$ & $13.5 \%$ \\
\hline Aggregate Mean & $22.19 *$ & $23.7 * *$ & 32.9 & $14.7^{* * *}$ \\
\hline
\end{tabular}

Numerical request had a significant effect (coeff. 1.00, $t=3.76, p<0.000$ ), but asking for more than equal division was costly (coeff. $-1.25, t=-3.02, p<0.001$ ). Table 2 shows why this is the case and the result is illustrated graphically in Figure 3. Subjects rarely got more than they asked for, with the exception being requests for quite low amounts and these requests comprise only $10.2 \%$ of all requests. Across conditions, $15 \%$ of requests for 40 were granted and $11 \%$ were exceeded. Of these passes that exceeded 40, the mean was 50. In contrast, 39\% of requests for 50 were granted. The difference $39 \%$ vs. $11 \%$ of subjects receiving 50 across these two requests is highly significant $(t=2.79, p<0.006)$ - asking is indeed powerful. However, asking for more than an equal division was detrimental; only 5\% of such requests were granted and none were exceeded. The mean pass for these "selfish requests" was less than half of the mean for the modal request of equal division and less than the mean in the baseline no-communication condition.

\section{Experiment 2 Results: Empathy as a Proximate Factor}

The patterns of communication content (Table 1) provide evidence that the positive effect of two-way communication on altruistic behavior is mediated by feelings of empathy. ${ }^{9}$ Experiment 2 tests this hypothesis directly by using one-way communication and intentionally heightening feelings of empathy towards one's partner (and this is common knowledge). Fig. 4A presents mean pass by condition of Experiment 2. The mean pass of "E with empathy" $(E(e))$ was 21.7 , which is significantly higher than $E(z=4.03$, $p<0.0001)$. The mean pass of "A with empathy" $(A(e))$, was 27.6 , which was greater than $A$, although

action is face-to-face. He argues that the requests can crowd-out pro-social motivation present in the face-to-face treatment. In our experiment, it is possible that mentioning the numerical requests crowded out the content of verbal communication.

${ }^{9}$ Note that we are only claiming this is altruistic behavior, not pure altruism. This leaves open the possibility that although empathy is a proximate factor, it is mediated through selfish channels, such as self-deception or guilt aversion. We address these points in detail in Section 4. 

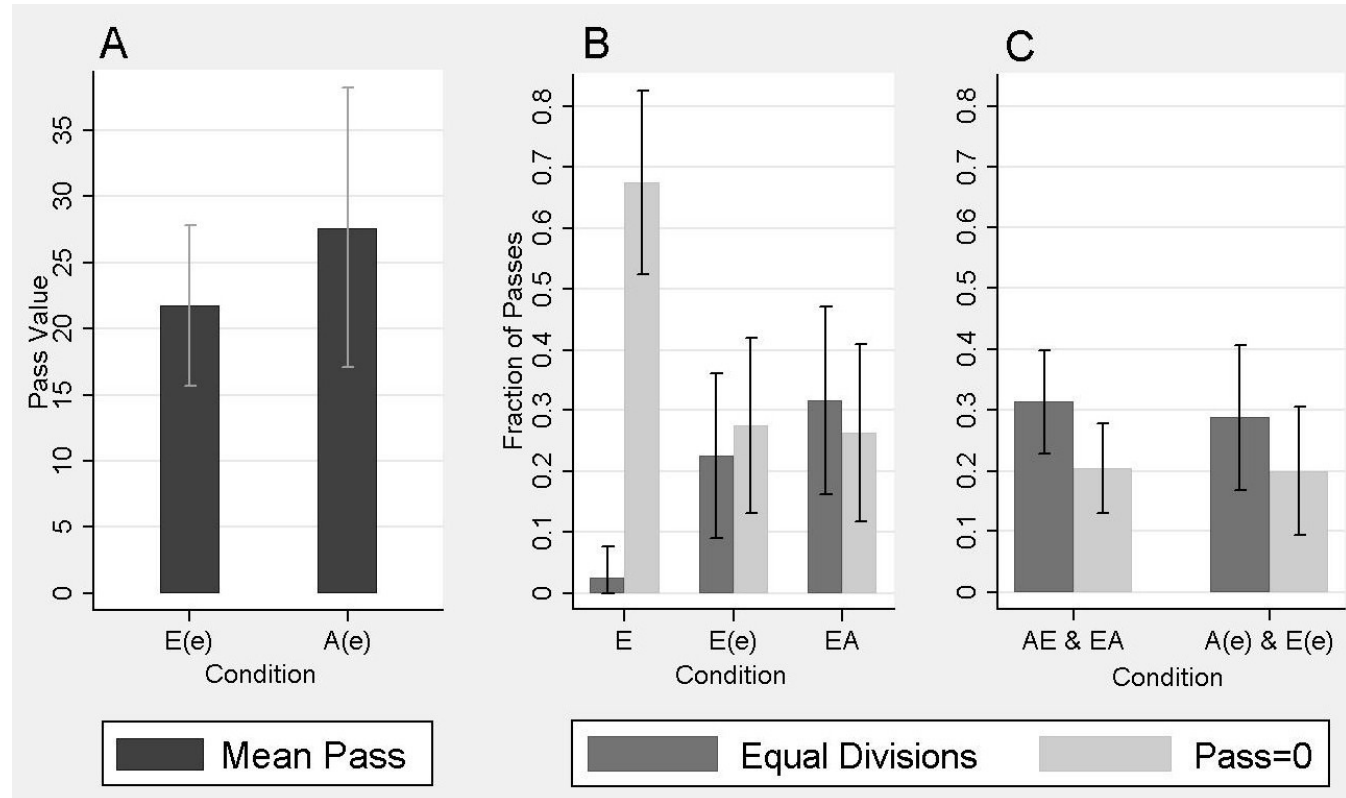

Figure 4: (A) Means of pass value by Experiment 2 condition: $A(e)(A$ with experimentally heightened empathy) and $E(e)$ ( $E$ with experimentally heightened empathy). (B) Fraction of equal divisions and pass $=0$ in conditions in which allocators "spoke" first. (C) Pooled comparison of the two-way communication in Experiment 1 and the "empathy" conditions of Experiment 2. Statistical tests given in Tables 1 and 3 fail to reject equality in distribution of pass value in $A E$ and $E A$ of Experiment 1 and $A(e)$ and $E(e)$ in Experiment 2. Bars give $+/-2$ s.e.

not significantly $(z=0.79, p<0.42)$ and very close to the generous behavior observed in the two-way conditions of Experiment $1(E A=27.0, A E=30.2)$. As hypothesized, the selfish behavior exhibited in $E$ was eliminated with the heightened empathy, just as it was with the existence of a subsequent request in $E A$. This is shown in Fig. 4B, which compares the fraction of equal divisions and zeros in all the conditions in which allocators spoke first.

Subjects exhibited significantly more generosity in both Experiment 2 conditions as compared to the baseline in Experiment 1, regardless of the fact they both involved one-way communication $(A(e) z=1.85$, $p<.032 ; E(e) z=1.45, p<0.073$ one-tailed $t$-test). ${ }^{10}$ Most interestingly, the distribution of choices in the empathy-inducing conditions in Experiment 2 were nearly identical to the true two-way communication conditions of Experiment 1. This is displayed graphically in Fig. 4C, which compares the pooled distribution of $E A \& A E$ to $E(e) \& A(e)$ (within each pool the conditions are not significantly different from each other). The distributions are virtually identical.

\footnotetext{
${ }^{10} \mathrm{We}$ use a one-tailed test here due to the bulk of evidence from the psychology literature that empathy increases observed generosity (Batson et al., 1988; Batson, 1991; Preston and de Waal, 2002).
} 


\section{Discussion}

In the introduction we argued that static inequity aversion did not match real-world inequality and that such "indiscriminate altruism" would not be a fit trait. ${ }^{11}$ We argued further that theoretical explanations for the underpinnings of altruism rely on people responding to social cues so that altruistic acts are meted out efficiently and to ensure the would-be altruist does not end up in the poor house, or worse. Brain imaging studies and traditional laboratory experiments have shown that in many contexts people have a strong aversion to inequality. However, in our daily lives we are exposed to inequality regularly, but take costly actions to lessen it only in special circumstances, such as when asked to give a charitable donation (Andreoni and Payne, 2003; Landry et al., 2006) or observed by an audience (Andreoni and Bernheim, 2009). Our view is that although one may feel the pangs of sympathy in the face of inequality (and associated brain activiation), the response is mediated by social cues and incentives, selfishness typically predominates.

The results of our experiments support this claim. In both experiments, factors such as the relative inequality and worthiness of the recipient were held constant. Subjects were always playing a DG in which one subject began with all the wealth and had an opportunity to share. In the condition in which roles were most asymmetric in terms of both power and speaking, $E$, we observed near universal selfishness (93\% of money was kept). When we modified $E$ so that receivers could respond to the written message before final allocation decisions were made $(E A)$, giving quadrupled. These differences were highly significant. Communication appears to be a powerful social cue in eliciting unselfish behavior. In the following subsection we examine why this the case.

\section{The Power of the Ask}

A natural view of communication is that it affects actions through its content alone (for a discussion see Mohlin and Johannesson, 2008). In this light, our results are surprising. The actual messages sent in the conditions with an "ask" mattered very little. One reason could be that the content of written requests appears obvious. One would presumably expect receivers to request 50-50 splits and extol fairness, which is precisely the modal message. This obviousness could explain why the verbal content of receivers' messages had no significant effect on allocations. This obviousness cannot, however, explain the primary finding of the paper that the fact of being asked matters tremendously, despite the fact that any request is obvious.

Figure 3 provides clear evidence of "the power of the ask." It presents fitted values of the role of numerical request on pass value across all conditions, the distribution of numerical requests and sample means for relatively frequent requests. Asking for more typically leads to a greater pass but with limits — subjects who requested more than an equal division were punished. So while "asking for the obvious" is effective, asking for more than one's fair share typically results in getting nothing in return.

This "paradox of obviousness," which has been studied in other contexts (Ellingsen and Johannesson, 2004; Charness and Dufwenberg, 2006; Charness and Rabin, 2005; Charness, 2000; Xiao and Houser,

\footnotetext{
${ }^{11}$ It is worth noting that indiscriminate altruism, roughly speaking, exists in what are known a eusocial species. Although exceedingly few species are eusocial, they are a few prolific examples such as ants and bees. Individual members of these species act to preserve the meta-organism (the hive) and many of their instincts go against self-preservation (for example, when a drone bee stings, it dies).
} 
2009), must be understood from two different perspectives. First, in $E$ the (unspoken) request the receiver would make was just as obvious as in $E A$, yet subjects in $E$ sent self-serving messages while in $E A$ they expressed less remorse and more fairness. ${ }^{12}$ Moreover, the mean of the non-binding allocation in $E A$ was four times that of the final allocation in $E(p<.0001)$ (final allocations in $E A$ were shaded up slightly from the non-binding allocation). The allocators in $E A$ were clearly successful in anticipating (and preemptively responding to) the ask, while those in $E$ were able "explain away" their selfishness. The giving behavior and verbal messages suggests that the communicative "joint attentional frame" differed significantly across these one and two-way communication conditions.

Second, allocators in $E$ not only were more selfish than in all conditions containing an ask, they were also significantly more selfish than the baseline, when both parties were silent. We saw that the predominant content of messages in $E$ was remorse. Often this was simply the words "I'm sorry." The baseline differed from $E$ in that expressing remorse was not possible. If expressing remorse could reduce one's guilt, then explaining one's choice could have an instrumental value to allocators in $E$ relative to the baseline. This explanation is consistent with previous findings of guilt aversion (Dufwenberg and Gneezy, 2000; Charness and Dufwenberg, 2006). Another related explanation is that $E$ facilitated self-deception. The allocator convinces himself that passing nothing and issuing an apology is a morally acceptable action. ${ }^{13}$

The interesting contrast is that explaining does not have the same instrumental value in $E A$ that it has in $E$. Instead, allocators in $E A$ are significantly more generous than both the baseline and $E$, and statistically indistinguishable from $A$ and $A E$. There are also on average one-fourth as likely to issue an apology. Asking, it appears, has the power to neutralize any value of explaining. When the allocator does not have to consider the other's position through communication or experimentally induced empathy, this self-deception and guilt avoidance comes at low cost. When pushed to form more precise beliefs about the other's position, these self-serving rationalizations are defanged.

The findings of Experiment 1 confirm our primary hypothesis that communication can greatly influence the level of altruistic behavior. Studying the "pure" incentives by ignoring this social component of giving will hide significant aspects of giving behavior.

\section{The Advantage of Empathy}

These findings led to our secondary hypothesis: the existence of communication from the receiver to the allocator increases the allocator's empathy with the receiver. In Experiment 2, we initially placed subjects in roles of both allocator and recipient, and then randomly determined which of the two roles to use for the completion of the games and determination of monetary payments. Since the subjects made both $A$ and $E$ decisions, they had to put themselves in the mindsets of both roles.

The data strongly support our hypothesis. Subjects in $E(e)$, who faced no ask, were significantly more altruistic than $E$ subjects, and statistically indistinguishable from the $E A$ subjects, who actually did face an ask (Fig. 2B). That is, having to formulate an (unused) ask themselves was as effective as facing an

\footnotetext{
${ }^{12}$ Xiao and Houser (2009) find that allowing recipients to complain ex-post leads to more generous behavior.

${ }^{13}$ There is evidence that people misperceive requests based on which "side" they are on. Bohns et al. (2010) demonstrates that people underestimate the discomfort of seeking assistance, which helps explain why they do not help in the absence of an "ask."
} 
actual ask from another subject. Our inference is that two-way communication leads one to appreciate and identify the other's position more fully (which we call empathy). This inference is motivated by the fact that an essential (and unique) feature of human communication is what linguists call recursive mindreading (forming beliefs about the other's beliefs). ${ }^{14}$ Facing an ask, be it explicitly or implicitly through empathic reasoning, blocks self-serving communication and selfish choices.

Although there has been a large amount of work linking empathy and pro-social behavior (see a review in Batson, 1991), it has not been established that empathy increases "pure altruism" (genuine concern for others). Three channels of impure altruism have been the subject of recent attention in the literature: concerns for social-image (Andreoni and Bernheim, 2009; Tadelis, 2008; Ariely et al., 2009), self-image and self-signaling (Bodner and Prelec, 2003; Dana et al., 2007) and guilt aversion (Charness and Dufwenberg, 2006; Battigalli and Dufwenberg, 2007). In our experiment, social distance and anonymity remained constant, so the results are unlikely to be explained by differing concerns for social image. We discuss the other two channels below.

Past work has defined guilt aversion to be proportional to the degree to which the action falls short of recipient's expectations ("let down aversion") (Dufwenberg and Gneezy, 2000; Charness and Dufwenberg, 2006). This interpretation works well for Experiment 1 conditions $E, A$ and $A E$, under the assumption that requests (in part) form receiver's expectations (and allocator's recognize this). The prevalence of apologies in $E$ is also supportive as apologies are associated with feelings of guilt (Tangney, 1995). However, it has trouble explaining why behavior in $E A$ is so similar to $A E$ and so different from $E$. One would expect the allocator to use the first message (non-binding allocation and verbal) to depress receiver's expectations in order to reduce guilt, but non-binding allocations are generous and the message content does not mirror that in $E$. Furthermore, in the $E(e)$ condition of Experiment 2, allocators never receive any actual communication and yet still give much more than $E$ and more than the baseline. This indicates that apologies and efforts to intentionally depress expectations lose their force in the face of empathy, whether it is induced by an ask or through direct consideration of both roles as in Experiment 2, because the issuer is more likely to see the apology as unsatisfactory (he would not find it satisfactory were he the receiver). Our view is that guilt aversion can only explain the results if empathy limits the effectiveness of strategies to reduce guilt; guilt aversion based solely upon the recipient's expectations (as opposed to a biased perception) is difficult to reconcile with all our experimental findings. ${ }^{15}$ Strategically biased perception of the other's beliefs could explain the findings if it is the case that without communication, it is easier for the allocator to manipulate his beliefs and convince himself that the receiver's expectation is low (perhaps because he does not fully consider the other's position). Under this view, guilt aversion is the driver of behavior and expectations are endogenous to communication and belief formation about the other's position.

The argument in favor of self-image maintenance rests upon self-signaling and strategic ignorance. The

\footnotetext{
${ }^{14}$ Great apes appear to have the capacity for level-1 mindreading only. For example, in the game of hind-and-seek an ape can correctly recognize what the seeker can and cannot see during hiding process. But they do not act in a way that is consistent with recognizing that other apes recognize this as well, whereas human toddlers do (Call and Tomasello, 1999). Level-2 mindreading is required for anything beyond very basic communication, as such, this sort of communication is distinctly human (Tomasello, 2008).

${ }^{15}$ As mentioned earlier, the empathy in this study was in a sense always "common knowledge of empathy" in that recipients knew allocators would read the messages and everyone knew their fellow subjects filled out decision forms from both roles.
} 
basic premise is that allocator's do not consider the other's position if they do not have to. An analog is the finding by Dana et al. (2007) that roughly half of subjects willfully remain ignorant about how their actions will affect their counterpart in a modified dictator game or that people on the street "avoid the beggar" (Dana et al., 2006). Grossman (2010) revisits the Dana et al. (2007) game and replicates the finding that half of subjects remained ignorant when it was the default choice, but also finds that only $25 \%$ actively chose ignorance when no default was provided and that only $3 \%$ chose ignorance when knowledge of the other's payoffs was the default. Our results have a similar tone. In the Experiment 1 conditions with an ask, the situation moves from one which the allocator has the potential to know the recipient's feelings (baseline) to one in which she is forced, based on the belief formation associated with verbal communication, to actually consider her. ${ }^{16}$ This knowledge raises the cost of self-deception. An active understanding of the position of the other is precisely what we have defined as empathy. As such, under this interpretation, empathy promotes altruistic behavior by making self-deception more difficult and self-signaling more costly.

The results of Experiment 2 are consistent with this interpretation. Many subjects found it difficult to simultaneously request a fair division and administer a stingy one. But subjects who did pass 0 were just as likely as other subjects to request an equal split. It is interesting that the subjects that were not moved from a position of selfishness by this intervention seemingly had no trouble requesting a bulk of the pie and typically included a verbal message. However, $63 \%$ of these subjects did not communicate verbally in $E(e)$, far more than the $14.8 \%$ observed in $E$ for subjects sending 0 .

The question of how empathy promotes altruism is an interesting one we leave to future research. We note that our results are consistent with both the more traditional view that empathy generates a genuine concern for others (Batson, 1991) and the view that it operates through self-interest, either by raising the cost of self-deception or by blocking strategies that ameliorate guilt.

\section{Conclusion}

Our results highlight the importance of the social component of giving and assert that studying giving without considering communication between the giver and recipient has the potential to overlook many valuable insights. Because standard explanations for the existence of altruistic behavior in humans, especially among non-kin, rely heavily on the social nature of our species, a direct study of the social factors that affect altruistic behavior is a natural and important step in furthering our understanding. Our study introduces communication into an economic experiment and shows that communication, especially the power of asking, greatly influences feelings of empathy and pro-social behavior. It suggests that selfishness typically predominates and the human capacity for altruism is activated through social cues. Humans have evolved the dual capacities to both be very compassionate and to put on blinders to protect us from our naturally altruistic tendencies. Communication from recipients, be it real or inferred through introspection, is one way that our species triggers the empathy required to remove these protective blinders.

\footnotetext{
${ }^{16}$ We thank a referee for this helpful distinction.
} 


\section{References}

Akhtar, N., Carpenter, M., and Tomasello, M. (1996). The role of discourse novelty in early word learning. Child Development, pages 635-645.

Andreoni, J. (2006). Philanthropy. In Kolm, S. and Ythier, J., editors, Handbook on the Economics of Giving, Reciprocity and Altruism, pages 1201-1269. Elsevier.

Andreoni, J. and Bernheim, B. (2009). Social image and the 50-50 norm: A theoretical and experimental analysis of audience effects. Econometrica, 77(5):1607-1636.

Andreoni, J. and Miller, J. (2002). Giving according to GARP: An experimental test of the consistency of preferences for altruism. Econometrica, 70(2):737-753.

Andreoni, J. and Payne, A. (2003). Do government grants to private charities crowd out giving or fundraising? American Economic Review, 93(3):792-812.

Ariely, D., Bracha, A., and Meier, S. (2009). Doing good or doing well? Image motivation and monetary incentives in behaving prosocially. American Economic Review, 99(1):544-555.

Batson, C. (1991). The altruism question: Toward a social psychological answer. Lawrence Erlbaum Assoc Inc.

Batson, C. (2002). Addressing the altruism question experimentally. In Post, S., Underwood, L., Schloss, J., and Hurlbut, W., editors, Altruism and Altruistic Love. Oxford University Press.

Batson, C., Dyck, J., Brandt, J., Batson, J., Powell, A., McMaster, M., and Griffitt, C. (1988). Five studies testing two new egoistic alternatives to the empathy-altruism hypothesis. Journal of Personality and Social Psychology, 55(1):52.

Battigalli, P. and Dufwenberg, M. (2007). Guilt in games. The American Economic Review, 97(2):170-176.

Bodner, R. and Prelec, D. (2003). The diagnostic value of actions in a self-signaling model. In Brocas, I. and Carillo, J., editors, The Psychology of Economic Decisions, vol. Rationality and Well-being, volume 1. Oxford University Press.

Bohnet, I. and Frey, B. (1999). The sound of silence in prisoner's dilemma and dictator games. Journal of Economic Behavior and Organization, 38(1):43-57.

Bohns, V. and Flynn, F. (2010). Why didnt you just ask? Underestimating the discomfort of help-seeking. Journal of Experimental Social Psychology, 46(2):402-409.

Bolton, G. and Ockenfels, A. (2000). ERC: A theory of equity, reciprocity, and competition. The American Economic Review, 90(1):166-193. 
Boyd, R. and Richerson, P. (1992). Punishment allows the evolution of cooperation (or anything else) in sizable groups. Ethology and Sociobiology, 13(3):171-195.

Call, J. and Tomasello, M. (1999). A nonverbal false belief task: The performance of children and great apes. Child Development, 70(2):381-395.

Charness, G. (2000). Self-serving cheap talk: A test of Aumann's Conjecture. Games and Economic Behavior, 33(2):177-194.

Charness, G. and Dufwenberg, M. (2006). Promises and partnership. Econometrica, 74(6):1579-1601.

Charness, G. and Rabin, M. (2005). Expressed preference in experimental games. Games and Economic Behavior, 53.

Clark, H. (1992). Arenas of Language Use. Center for the Study of Language.

Crawford, V. and Iriberri, N. (2007). Level-k auctions: Can a nonequilibrium model of strategic thinking explain the winner's curse and overbidding in private-value auctions? Econometrica, 75(6):1721-1770.

Dana, J., Cain, D., and Dawes, R. (2006). What you don't know won't hurt me: Costly (but quiet) exit in dictator games. Organizational Behavior and Human Decision Processes, 100(2):193-201.

Dana, J., Weber, R., and Kuang, J. (2007). Exploiting moral wiggle room: experiments demonstrating an illusory preference for fairness. Economic Theory, 33(1):67-80.

De Quervain, D., Fischbacher, U., Treyer, V., Schellhammer, M., Schnyder, U., Buck, A., and Fehr, E. (2004). The neural basis of altruistic punishment. Science, 305(5688):1254-1258.

De Vignemont, F. and Singer, T. (2006). The empathic brain: How, when and why? Trends in Cognitive Sciences, 10(10):435-441.

Decety, J. and Jackson, P. (2006). A social-neuroscience perspective on empathy. Current Directions in Psychological Science, 15(2):54-58.

Dufwenberg, M. and Gneezy, U. (2000). Efficiency, reciprocity, and expectations in an experimental game. Games and Economic Behavior, 30:163-182.

Ellingsen, T. and Johannesson, M. (2004). Promises, threats and fairness. The Economic Journal, 114(495):397-420.

Fehr, E. and Fischbacher, U. (2003). The nature of human altruism. Nature, 425(6960):785-791.

Fehr, E. and Schmidt, K. (1999). A theory of fairness, competition, and cooperation. Quarterly Journal of Economics, 114(3):817-868.

Forsythe, R., Horowitz, J., Savin, N., and Sefton, M. (1994). Fairness in simple bargaining experiments. Games and Economic Behavior, 6(3):347-369. 
Grice, H. (1957). Meaning. The Philosophical Review, pages 377-388.

Grossman, Z. (2010). Strategic ignorance and the robustness of social preferences. UCSB Working Paper.

Gurerk, O., Irlenbusch, B., and Rockenbach, B. (2006). The competitive advantage of sanctioning institutions. Science, 312(5770):108-111.

Hamilton, W. (1964). The genetical evolution of social behaviour. Journal of Theoretical Biology, 7(1):1.

Harbaugh, W., Mayr, U., and Burghart, D. (2007). Neural responses to taxation and voluntary giving reveal motives for charitable donations. Science, 316(5831):1622.

Hare, B., Call, J., and Tomasello, M. (2001). Do chimpanzees know what conspecifics know? Animal Behaviour, 61(1):139-152.

Hare, T., Camerer, C., Knoepfle, D., O’Doherty, J., and Rangel, A. (2010). Vale computations in ventral medial prefrontal cortex during charitable decision making incorporate input from regions involved in social cognition. The Journal of Neuroscience, 30(2):583-590.

Hoffman, E., McCabe, K., and Smith, V. L. (1996). Social distance and other regarding behavior in dictator games. American Economic Review, 86(3):653-660.

Landry, C., Lange, A., List, J., Price, M., and Rupp, N. (2006). Toward an understanding of the economics of charity: Evidence from a field experiment*. Quarterly Journal of Economics, 121(2):747-782.

Masclet, D., Noussair, C., Tucker, S., and Villeval, M. (2003). Monetary and nonmonetary punishment in the voluntary contributions mechanism. American Economic Review, 93(1):366-380.

Mohlin, E. and Johannesson, M. (2008). Communication: Content or relationship? Journal of Economic Behavior and Organization, 65(3-4):409-419.

Moll, J., Krueger, F., Zahn, R., Pardini, M., de Oliveira-Souza, R., and Grafman, J. (2006). Human frontomesolimbic networks guide decisions about charitable donation. Proceedings of the National Academy of Sciences, 103(42):15623.

Nowak, M. and Sigmund, K. (2005). Evolution of indirect reciprocity. Nature, 437:1291.

Preston, S. and de Waal, F. (2002). Empathy: Its ultimate and proximate bases. Behavioral and Brain Sciences, 25(1).

Rankin, F. (2006). Requests and social distance in dictator games. Journal of Economic Behavior and Organization, 60(1):27-36.

Roth, A. (1995). Bargaining Experiments. In Kagel, J. H. and Roth, A., editors, Handbook of Experimental Economics. Princeton, NJ: Princeton University Press. 
Schelling, T. (1968). The life you save may be your own. Problems in Public Expenditure Analysis, pages $127-162$.

Small, D. and Loewenstein, G. (2003). Helping a victim or helping the victim: Altruism and identifiability. Journal of Risk and Uncertainty, 26(1):5-16.

Tadelis, S. (2008). The power of shame and the rationality of trust. SSRN Working Paper: http://ssrn.com/abstract $=1006169$.

Tangney, J. (1995). Recent advances in the empirical study of shame and guilt. American Behavioral Scientist, 38(8):1132.

Tomasello, M. (2008). Origins of Human Communication. The MIT Press.

Tricomi, E., Rangel, A., Camerer, C., and ODoherty, J. (2010). Neural evidence for inequality-averse social preferences. Nature, 463(7284):1089-1091.

Trivers, R. (1971). The evolution of reciprocal altruism. The Quarterly Review of Biology, 46(1):35.

Xiao, E. and Houser, D. (2005). Emotion expression in human punishment behavior. Proceedings of the National Academy of Sciences, 102(20):7398-7401.

Xiao, E. and Houser, D. (2009). Avoiding the sharp tongue: Anticipated written messages promote fair economic exchange. Journal of Economic Psychology, 30(3):393-404. 


\section{Appendix}

\subsection{Supplementary Tables}

Supplementary Table 1: Random-effects Tobit regression of pass value on request characteristics.

\begin{tabular}{|c|c|c|}
\hline & (1) & (2) \\
\hline Request & $\begin{array}{l}0.761 * \\
(0.444)\end{array}$ & $\begin{array}{c}1.000 * * * \\
(0.266)\end{array}$ \\
\hline Request* $1\{$ Request $>50\}$ & $\begin{array}{l}-1.072 \\
(0.740)\end{array}$ & $\begin{array}{c}-1.250 * * * \\
(0.414)\end{array}$ \\
\hline $1\{$ Request $>50\}$ & $\begin{array}{c}30.38 \\
(48.98)\end{array}$ & $\begin{array}{c}35.00 \\
(28.70)\end{array}$ \\
\hline Power & $\begin{array}{c}3.134 \\
(13.58)\end{array}$ & \\
\hline Need & $\begin{array}{l}-11.41 \\
(12.18)\end{array}$ & \\
\hline Friendly greeting & $\begin{array}{l}-1.393 \\
(15.94)\end{array}$ & \\
\hline Fairness & $\begin{array}{l}-3.831 \\
(11.98)\end{array}$ & \\
\hline Flattery & $\begin{array}{c}2.438 \\
(16.72)\end{array}$ & \\
\hline round 1 & $\begin{array}{c}1.194 \\
(7.068)\end{array}$ & \\
\hline Constant & $\begin{array}{c}0.746 \\
(18.90)\end{array}$ & $\begin{array}{c}-10.0 \\
(12.21)\end{array}$ \\
\hline Observations & 156 & 156 \\
\hline
\end{tabular}

Supplementary Table 2: Wilcoxon rank-sum $z$-scores for difference in distribution by condition of Experiment 1.

\begin{tabular}{lcccc} 
& \multicolumn{4}{c}{ Condition } \\
\cline { 2 - 5 } & $A$ & $E$ & $A E$ & $E A$ \\
\hline Baseline & -1.26 & $2.73^{* * *}$ & $-3.29^{* * *}$ & $-2.04^{* *}$ \\
$A$ & & $3.69^{* * *}$ & -1.46 & -0.68 \\
$E$ & & & $-5.94^{* * *}$ & $-4.38^{* * *}$ \\
$A E$ & \multicolumn{3}{c}{} & 0.64 \\
\hline \multicolumn{3}{r}{$p<0.01,{ }^{* *} p<0.05$}
\end{tabular}

Supplementary Table 3: Wilcoxon rank-sum $z$-scores for difference in distribution.

\begin{tabular}{cccccc} 
& \multicolumn{5}{c}{ Experiment 1 Condition } \\
\cline { 2 - 5 } Experiment 2 Condition & Baseline & $A$ & $E$ & $A E$ & $E A$ \\
\hline$E(e)$ & $1.45^{*}$ & -0.187 & $4.03^{* * *}$ & $-1.875^{*}$ & -0.90 \\
$A(e)$ & $1.83^{* *}$ & 0.79 & $3.73^{* * *}$ & 0.78 & -0.181 \\
\hline${ }^{* * *} p<0.01,{ }^{*} p<0.1$ indicate significance, one-tailed test except in comparison to $A E \& E A$
\end{tabular}




\subsection{Experiment 1 Instructions Sample: Condition $A E$}

Welcome and thank you for participating in this study. For agreeing to participate you will automatically earn a $\$ 7$ "thank you" payment. Anything you earn in the study will be added to this.

\section{Confidentiality}

We promise you total anonymity and confidentiality in this study. We will never record your name anywhere and no other participant will ever be able to tie you to the decisions you make. Whatever you earn will be paid to you in a sealed envelope. As a result, not even those running the study will be able to connect you to the decisions you made.

\section{Quiet Please}

During this study, please do not talk or make any other audible noises. This is very important. Any talking will mean that we will have to cancel the study.

Thank you for your cooperation.

\section{This Study}

In this study you will be paired with one other participant for a single decision. The actions you and the other subject take will result in dividing 100 tokens between the two of you. Tokens are worth $\$ 0.10$ each. This means you will be determining the allocation of $\$ 10$ between the two participants.

After this decision you will be randomly re-matched with one other participant and make another decision like that just described. Again you will allocate 100 tokens, that is, $\$ 10$. Your role in the decisions will be the same both times.

After this decision the study will be complete and we will prepare your payments.

\section{The Allocation}

One of the two participants in your pair will be randomly selected as the Allocator. This will be called Person A. The other participant will be called the Receiver, or Person R. Person A will choose an allocation for the pair. Person A will do this by filling in the blanks in this statement:

"Of the 100 tokens, I choose to hold for myself and pass to Person R.”

Person A's decision will determine the final payoffs for both Person A and Person R.

\section{The Stages for this Study}

There will be several stages to the study. These stages will be conducted by having each pair of participants fill out a Decision Form. We will pass the form back and forth between participants in such a way that the two participants cannot identify each other. This is how the stages will work.

Stage 1: Person $\mathrm{R}$ can make a request to Person A by filling in the spaces like this: 


\section{Stage 1: Person R moves.}

$R$ 's Request to $A$ : Please fill out your decision in Stage 2 this way:

Of the 100 tokens, I choose to hold for myself and pass to Person R.

In the space below, you may record a message to Person A.

In addition, Person R can write a message to Person A in the space provided. The message can say anything. The only restriction is that it contain no information that could allow participants to identify each other.

We will then carry the form to Person A for the next stage.

Stage 2: Person A chooses the allocation of the 100 tokens by filling in blanks in this line of the Decision Form:

Stage 2: Person A moves.

Of the 100 tokens, I choose to hold for myself and pass to Person R.

(Note: The amounts in hold and pass must sum to 100 . Each token is worth $\$ 0.10$.)

Chosen Allocation: Person A earns \$ and Person R earns \$

In the space below, you may record a message to Person $\mathrm{R}$.

Note: The amounts in hold and pass must sum to 100 .

Person A will get the tokens in the hold portion and Person R will get the tokens in the pass portion. However, Person A can hold any number from 0 to 100, including 0,100 and any number in between. 
When Person A has chosen the allocation of tokens, he/she will write the allocation in terms of dollars in the space provided (remember, each token is worth $\$ 0.10$ ).

In addition, Person A can write a message to Person $\mathrm{R}$ in the space provided. The message can say anything. The only restriction is that it contain no information that could allow participants to identify each other.

We will then carry the form to Person $\mathrm{R}$ for the next stage.

Stage 3: Person R must see the message from Person A and acknowledge this by checking the box at the bottom of the decision form.

This ends a round.

\section{The Two Rounds}

After all the stages described above are complete we will reassign people to new partners and we will begin the second round of decisions. No one will know anything about their partner's decisions and outcomes in the first round. The second round will be conducted the same way as the first. The study will end after the second round.

\section{Your Earnings}

At the end of the second round, we will prepare your payments. This includes the $\$ 7$ "thank you' payment, plus the earnings from the allocation of the 100 tokens in the two rounds.

We will place each person's earnings in a sealed envelope. We will pay participants in the role of Person A first and allow them to leave. We will then pay those in the role of Person $\mathrm{R}$ and allow them to leave.

\section{Your Role}

After everyone has read the instructions we will flip a coin to determine who will play which role. You will stay in the same role for both decision rounds.

If HEADS: Odds will be Person A, Evens will be Person R

If TAILS: Evens will be Person A, Odds will be Person R

\section{Things to Remember}

1. You automatically get a $\$ 7$ "thank you' payment.

2. Your confidentiality is assured.

3. Quiet Please. No audible sounds can be permitted.

4. There will be two decision rounds.

5. For each decision round you will be paired with a different participant.

6. You will be assigned the role of Person A, the Allocator, or Person R, the Recipient. You will stay in that role for both decision rounds.

7. Person A has the choice of how to allocate the 100 tokens.

8. Each token you earn is worth $\$ 0.10$. Hence, the most you can earn in the study is $\$ 27$, the least is $\$ 7$ (including the $\$ 7$ "thank you' payment), or you can earn anything in between.

9. We will pay in cash in a sealed envelope at the end of the study. 
Once all questions have been answered we will begin by flipping a coin to determine your role.

\subsubsection{Experiment 2 Instructions}

\section{Welcome}

Welcome and thank you for participating in this study. For agreeing to participate you will automatically earn a $\$ 7$ "thank you" payment. Anything you earn in the study will be added to this.

\section{The Two Decision Tasks}

Today's study includes two separate decision tasks, which we will call Decision Task X and Decision Task Y. Each of the tasks has several things in common.

- Both Decision Tasks will pair you with an anonymously chosen person on the other side of the room. IMPORTANT: For each decision task, you will be paired with a different anonymous participant.

- Both Decision Tasks assign roles to the two participants in each pair. As you will see, one role is called Player A, and the other is called Player R. IMPORTANT: When we select roles, you will be in the same role for both decision tasks

- Both Decision Tasks have several stages where players alternate activities. We conduct this by passing a Decision Form between the players in each pair until all the stages are complete..

The two decision tasks have some differences as well.

- In Decision Task X, Person R moves in Stage 1, Person A moves in Stage 2, etc.

- In Decision Task Y, Person A moves in Stage 1, Person R moves in Stage 2, etc.

Shortly, we will be going over the Directions for both Decision Tasks X and Y.

\section{Making Stage 1 Decisions}

Before we assign you your role today, we are going to ask you to make the Stage 1 decisions for both roles. That is, you will make the Stage 1 decision for Decision Task X as if you are in the role of Person R, and you will make the Stage 1 decision for Decision Task Y as if you are in the role of Person A.

After everyone has made the Stage 1 decisions for both decision tasks we will flip a coin to determine who will play which role. You will stay in the same role for both decision tasks.

If HEADS: Odds will be Person A, Evens will be Person R

If TAILS: Evens will be Person A, Odds will be Person R

IMPORTANT: Since it is equally likely that you will be in either role, it is in your interest to make the Stage 1 decisions for each role as if you were actually known to be in that role. 


\section{If you are chosen to be Person A:}

We will carry out your Stage 1 decision from Decision Task Y.

We will set aside your Stage 1 decision form for Decision Task X. What you did in Stage 1 for Decision Task $\mathrm{X}$ will never be seen by another person in the study.

\section{If you are chosen to be Person R:}

We will carry out your Stage 1 decision from Decision Task X.

We will set aside your Stage 1 decision form for Decision Task Y. What you did in Stage 1 for Decision Task Y will never be seen by another person in the study.

\section{Making Stage 2 Decisions}

If you are chosen to be Person A:

Your Decision Form for Task X will be carried to an anonymous person in the Role of Person R, who will then make the Stage 2 decision for Decision Task X.

You will also receive a Decision Form for Decision Task Y from a different anonymous person in the role of Person R and will be asked to make a Stage 2 decision in Decision Task Y.

\section{If you are chosen to be Person R:}

Your Decision Form for Task Y will be carried to an anonymous person in the Role of Person A, who will then make the Stage 2 decision for Decision Task X. You will also receive a decision form for Decision Task $\mathrm{X}$ from a different anonymous person in the role of Person $\mathrm{A}$ and will be asked to make a Stage 2 decision in Decision Task X.

\section{Your Earnings}

At the end of all the decisions, we will add your earnings from Decision Task X and Decision Task Y, plus the $\$ 7$ thank you payment. We will place each person's earnings in a sealed envelope and hand them to you individually, by your participant number.

Next we will go over the directions for both Decision Tasks. Each Decision Task has separate directions, and separate Decision Forms. After we have gone over all the directions, you can fill out the Stage 1 decisions for both Task X and Task Y. You may fill them out in any order you like.

When you have finished, please put the Decision Form for Decision Task X in the envelope marked "X", and put the Decision Form for Decision Task Y in the envelope marked "Y". When everyone is done with both decisions, we ill collect all the Decision Forms. At that point we will flip a coin to determine roles.

IMPORTANT: Do not make any decisions until we have gone over the directions for both Decision Tasks, and the Experimenter instructs you that you can begin making decisions. Thank you for your cooperation.

We will now begin reading the directions for the two decision tasks.

(Both decision tasks were then explained just as in Experiment 1) 


\subsection{Instructions to Reviewers and Precise Definitions of Communication Categories}

\section{Structure of the Game}

In the DG there are two players: the allocator and the receiver. A coin toss determines role assignment. The allocator is given ten dollars to split between herself and the receiver. She can pass to the receiver any dollar amount from zero to ten.

In some conditions of the experiment, subjects were allowed to communicate via written messages. There were two types of communication: ask and explain. The ask phase allowed receivers to send a message requesting a certain portion of the ten dollar pie, along with a written message. The explain phase allowed allocators to send a written message along with the pass amount. The experimental conditions were varied such that some contained no forms of communication, while others contained one or two. The order was also changed. For the DG there were the following conditions: ask only, explain only, ask then explain and explain then ask. Note that for the explain then ask, allocators also sent a non-binding numerical "proposed" allocation.

Each subject played two rounds of the game (condition remained the same) with two different partners. For example, for the DG ask-explain condition, the game was played as follows.

1. Receiver sends a written message to the allocator, along with a numerical pass request.

2. The allocator chooses the pass amount and sends it to the receiver along with a written message.

3. The players are paid according to the split determined by the allocator.

It is important to remember the order of the communication when analyzing the content of the messages. For instance, for the "explain then ask" condition, the explain message should be coded first followed by the ask condition. Also it is important to note the numerical request (or non-binding proposal) because the subjects would read and interpret the message with the request in mind as well. Basically you want to read the communication as a subject would (i.e. in the right order and using all information available to the subject) and analyze the content. The spreadsheet provided to you will contain columns for each condition. For example if you see a 1 in the "ask then explain" column this means that was the condition used. In every condition except "explain then ask" the communication (if applicable) order is: ask, explain, comment. So you really just need to watch out for the "explain then ask" condition and be sure to read the explains first for this case.

The following section explains precisely how the content will be analyzed.

\section{Coding the communication}

Each form of communication needs to be categorized according to its content. These categories are not exclusive, that is a message could very well fit into two or more categories. The categories were chosen to limit the inherent subjectivity in determining the content of the message. Please read these guidelines carefully.

In the coding spreadsheet you have been provided with you will notice that to the right of the column containing the written communication there are columns with the appropriate communication categories. For instance, next to the column labeled "Ask" there are columns labeled "a_fairness", etc. After reading the message you will put a 1 in a column if you feel it qualified as that category of communication and 0 if it, in your opinion, did not qualify. Invariably there will be some judgment calls to be made, in these situations 
just try to be consistent and do your best.

\section{Receiver Communication}

\begin{tabular}{|c|c|c|}
\hline Category & Description & Example \\
\hline Fairness & $\begin{array}{l}\text { Appeals to fairness, equity, } \\
\text { equal division or similar moral value. }\end{array}$ & This seems like the fair way to go. \\
\hline Power & $\begin{array}{l}\text { Acknowledges the power that the } \\
\text { allocator has. }\end{array}$ & You have the control \\
\hline Flattery & $\begin{array}{l}\text { Contains a compliment or some } \\
\text { other form of flattery }\end{array}$ & I know you are a good person \\
\hline Need & Expresses a need for the money & I am broke, help me out \\
\hline Friendly Greeting & $\begin{array}{l}\text { Contains a greeting usually used } \\
\text { amongst friends }\end{array}$ & Hey, what's up :) \\
\hline
\end{tabular}

\begin{tabular}{lll} 
Category & \multicolumn{2}{c}{ Allocator Communication } \\
Remorse & $\begin{array}{l}\text { Expresses remorse and/or contains } \\
\text { an apology }\end{array}$ & Sorry! \\
Need & $\begin{array}{l}\text { Expresses need. } \\
\text { Mentions the good luck } \\
\text { they had in being chosen as allocator }\end{array}$ & $\begin{array}{l}\text { Sorry, I need the cash. } \\
\text { I won the coin toss. }\end{array}$ \\
You'd do it too & $\begin{array}{l}\text { States that the receiver would } \\
\text { do the same thing if they were allocator } \\
\text { Makes the point that the allocator } \\
\text { has all the power }\end{array}$ & This is what you'd do too.. \\
\hline
\end{tabular}

